\title{
The Core List Mirage: A Comparison of the Journals Frequently Consulted by Faculty and Students
}

\section{Kathleen E. Joswick and Jeanne Koekkoek Stierman}

\begin{abstract}
By employing a combination of electronic and manual methods, the authors of this study compiled separate lists of the journals most frequently used by Western Illinois University faculty and students. These lists of popular journals, although interesting in themselves, also reveal that journal consultation habits vary considerably between constituencies, even within one academic library. Thus, the ultimate "core list" remains illusory. The dissimilarity of the lists emphasizes the importance of using local data and recognizing the distinctive needs of both ends of the user spectrum when making journal-collection decisions.
\end{abstract}

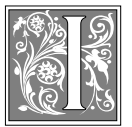

nformation professionals know that understanding the research behavior of local users is essential to building library collections that correspond to the unique needs of each institution. They repeatedly search for the ultimate "core list" of journals, the ones that best fit the needs of their primary clientele. Many past studies document librarians' efforts to gather journal consultation evidence beyond the purely anecdotal from reshelving data, circulation records, and citation statistics. These techniques, however, record the use of either only one group of customers (as in the citation studies) or all groups indiscriminately (as in the reshelving studies). As a result, journal selection and deselection has often been based on the research habits of specialized groups alone or on the assumption that all user needs are alike. Few would agree that university faculty and undergraduate students consistently consult the same journal literature. Yet, the authors have found no evidence of broad local studies that contrast journal usage by sophisticated researchers with that of undergraduate students.

The authors' goal was to remedy this lack, seeking to discover the extent of the discrepancy between faculty and student use and to explore any ramifications for the library's journal collection. Using a combination of electronic and manual methods, the authors compiled separate lists of journals "used" by Western Illinois University (WIU) faculty and students. The methods applied were, for the most part, comparatively quick and inexpensive, and at least as credible as many more traditional, labor-intensive

Kathleen E. Joswick is an Associate Professor in the Reference Unit of the University Library at Western Illinois University; e-mail: kate_joswick@ccmail.wiu.edu; Jeanne Koekkoek Stierman is an Associate Professor in the Reference Unit of the University Library at Western Illinois University; e-mail: jeanne_stierman@ccmail.wiu.edu. 
procedures. The resulting lists of high-use journals reveal interesting patterns of journal consultation that have application beyond the library at WIU.

\section{Methodology}

To distinguish between faculty and student use of serial literature, the authors devised techniques that matched the known research habits of the separate populations being investigated. They began their investigation by examining student use of journals. The first method of determining which journals students consult most frequently was to study reports

\section{All 4,266 references were thus identified and sorted, eliminating the need to find each article and check the citations individually.}

from Information Access Company (IAC) regarding WIU use of its Expanded Academic Index on InfoTrac. The journals indexed by Expanded Academic Index represent scholarly publications in many major fields of academic interest. InfoTrac promotes Expanded Academic Index as "the premiere CD-ROM database for undergraduate research," "and WIU reference librarians agree that this database is used almost exclusively by students at their institution. After setting each of the InfoTrac workstations to collect use data, the authors were able to download data files to a disk provided by IAC. From these files, the company compiled reports detailing the number of times a citation to each journal was retrieved from the database. These reports included lists of the indexed journals in both alphabetical order and ranked order by the number of retrievals. The "Count of Citations Printed" sorted each of the 1,379 journals in the index by its use at WIU workstations over a nine-month period, from March 23, 1993 , to January 3,1994 . Of the 1,379 journals indexed, 1,195 were retrieved more than once.
To see not only what students were selecting from an index but also what material they actually referenced in their research, the authors examined the journals cited by students in their papers. Margaret Sylvia and Marcella Lesher believe this to be "one of the best ways to measure past use of an academic library." 2 To ensure that the study considered the needs of those at the least sophisticated end of their user spectrum, the authors contacted WIU instructors of freshmen composition classes. Seven of them provided bibliographies from term papers written by their students. The cooperating instructors put no restrictions on either the topics chosen or the types of sources consulted. Two hundred four papers from spring 1991 classes yielded 532 citations to articles in 200 periodicals, eighty-nine of which were cited more than once.

Because faculty members are less likely than students to rely on an index to find journal articles, and certainly less likely to consult a general, multidis-ciplinary index, the authors could not rely on a replication of the Expanded Academic Index strategy that gave insight into student searches. ${ }^{3}$ Instead, to measure faculty journal use, they followed the examples of Stephanie C. Haas and Kate Lee ${ }^{4}$, and Keith Swigger and Adeline Wilkes ${ }^{5}$ by examining the journal titles in which WIU faculty published their research and the titles they cited in these publications. Using DIALOG to search the three Institute for Scientific Information (ISI) citation databases-Arts \& Humanities Citation Index, Science Citation Index, and Social Sciences Citation Index-the authors identified all the articles published between 1988 and 1992 whose authors were affiliated with WIU. The command string "cs=western()illinois and py=1988:1992" retrieved 473 articles published in 221 different journals.

For the second measure of faculty use, the authors investigated the journals cited in each of these published articles. DIALOG's "rank" command ("rank cw 
s5 cont detail") allowed them to group all the references by title of the journal or monograph cited and to record the total number of citations to each. All 4,266 references were thus identified and sorted, eliminating the need to find each article and check the citations individually. The journals cited more than once numbered 338.

Finally, to compare local use with international citation patterns, they looked at the most frequently cited journals as reported in ISI's Journal Citation Reports $(J C R)$. The authors totaled the number of citations to each of the fifty most frequently cited journals in Social Sciences Citation Index's and Science Citation Index's Journal Citation Reports between 1988 and 1992 to produce a list of the most cited journals for those five years. The fact that Arts \& Humanities Citation Index has no annual citation report makes no difference for these calculations. Because no Social Sciences Citation Index journals were cited enough to rank in the "top fifty" list, it can be assumed that titles from the even more widely scattered disciplines in arts or humanities would not replace any of the science journals topping the list.

These investigations have limitations. The studies covered time periods of differing lengths. Some samples were not very large. The ISI databases do not index any monographs and not all journals, so some faculty publications and their citations were missed. Also, the authors totaled only raw numbers of articles and citations, without weighting them to compensate for the fact that the number of articles in each journal varies widely. However, once recognized, the limitations do not adversely affect the overall conclusions of the study.

Initially, the authors analyzed data from both the top twenty-five and the top fifty journals in each category. The relationships among the lists and the patterns of overlap were so similar that, in the interest of brevity, the authors have focused attention on the shorter lists only. Any- one interested in seeing the fifty top journals in each category is invited to contact the authors.

Three of the five lists compiled from these studies do not contain exactly twenty-five journals. For cases in which a group of titles received the same number of citations or retrievals, the authors reduced or expanded the list to include all journals receiving the same number of references. Two lists, therefore, contain twenty-four titles and one list contains twenty-seven. Within each list, the journals that received the same number of citations or retrievals are listed in alphabetical order (see tables 1-5).

\section{Observations}

The most striking feature about these lists is their dissimilarity. There is very little crossover among the lists. Only two titles-Nature and Science-are on three of the five lists, and no titles are common to more than three. Sixty percent of all the titles appear on only one list-that is, seventy-five of the 125 journals are unique to one list. The worldwide and the faculty lists have lower percentages of shared titles than do the student lists: at most 38 percent of the titles from the international and faculty lists overlap with another list, whereas at least 52 percent of the students' titles overlap with another list.

The top twenty-five titles from $E x$ panded Academic Index (see table 1) were retrieved a total of 18,756 times, ranging from 5,226 references to the first title on the list (New York Times) to 331 references to the twenty-fifth title (Science). Few of these titles overlap with either the faculty or the international citation lists; there are no titles in common with the list of journals in which faculty publish, two with faculty citations (Nature and Science) and three with the worldwide list (Nature, Science, and Lancet). The greatest coincidence of titles is with the list of journals cited by students: thirteen of the twentyfive $(52 \%)$ were also cited by freshmen in 


\begin{tabular}{|c|}
\hline $\begin{array}{c}\text { TABLE } 1 \\
\text { Top Journals Retrieved from } \\
\text { InfoTrac Stations, in Ranked Order }\end{array}$ \\
\hline $\begin{array}{l}\text {-New York Times } \\
\text {-Time } \\
\text { JAMA: Journal of the American Medical } \\
\text { Association } \\
\text {-Business Week } \\
\text { Economist } \\
\text {-Newsweek } \\
\text {-Advertising Age } \\
\text {-U.S. News and World Report } \\
\text { Broadcasting } \\
\text {-Fortune } \\
\text { American Journal of Psychiatry } \\
\text { Congressional Quarterly Weekly Report } \\
\text { Variety } \\
\text { National Law Journal } \\
\text {-New Scientist } \\
\text { - Forbes } \\
\text { \#Nature } \\
\text {-Chronicle of Higher Education } \\
\text {-Lancet } \\
\text {-Science News } \\
\text { USA Today (magazine) } \\
\text { American Family Physician } \\
\text {-Maclean's } \\
\text {-Sports Illustrated } \\
\text { \#Science }\end{array}$ \\
\hline $\begin{array}{l}\text {-Title is on two lists. } \\
\text { \#Title is on three lists. }\end{array}$ \\
\hline
\end{tabular}

their term papers. This InfoTrac list has the largest number of titles appearing elsewhere ( $64 \%$ of the titles are on at least one other list). All twenty-five titles are current subscriptions at the WIU Library.

The top twenty-five journals in the student citation list (see table 2) were cited a total of 258 times, a much smaller sample size than the InfoTrac study. The New York Times and Newsweek tied for first place on the list with twenty-two citations each; the last group of titles (from Maclean's to Working Woman) received five citations each. Although the credibility of such a small sample could be challenged, it is interesting to note that two of the top three journals were the same on both stu-

\begin{tabular}{|l|}
\hline \multicolumn{1}{c|}{ TABLE 2} \\
Top Journals Cited in Freshman \\
Papers, in Ranked Order \\
\hline \hline •New York Times \\
• Newsweek \\
-Time \\
•Business Week \\
•Sports Illustrated \\
•Fortune \\
-U.S. News and World Report \\
Psychology Today \\
• Forbes \\
Peoria Journal Star \\
• Science News \\
Western Courier \\
•Advertising Age \\
•Chronicle of Higher Education \\
Current Health 2 \\
•New Scientist \\
Chicago Tribune \\
Macomb Journal \\
National Geographic Magazine \\
National Review \\
Nation's Business \\
•Maclean's \\
•New England Journal of Medicine \\
Working Woman \\
\hline -Title is on two lists. \\
\hline
\end{tabular}

dent lists. These freshmen citation titles do not overlap with either of the faculty lists, and only one title (New England Journal of Medicine) overlaps with the worldwide list. However, more than half of the titles (thirteen, or 54\%) also appear on the InfoTrac list. General undergraduate use corresponds more closely, it may be assumed, to freshman use than to faculty or international use, an important point for collection managers to keep in mind. One distinctive feature of this group of periodicals is the preponderance of such local publications as newspapers from area cities and the WIU campus paper. Freshmen researchers evidently rely more on regional works than do the other groups, probably because of the nature of the topics they study and their desire for readily accessible, convenient sources. 


\begin{tabular}{|l|}
\multicolumn{1}{c|}{ TABLE 3 } \\
Top Journals in Which \\
Faculty Publish, in Ranked Order \\
\hline \hline \\
Journal of Developing Areas \\
World Literature Today \\
Abstracts of Papers of the American \\
Chemical Society \\
-Journal of Social Psychology \\
Modern Language Journal \\
Bulletin of the Psychonomic Society \\
Mutation Research \\
Professional Geographer \\
•Psychological Reports \\
-Journal of Parasitology \\
Historian \\
International Journal for the \\
Advancement of Counseling \\
Classical World \\
Journal of Freshwater Ecology \\
Sixteenth Century Journal \\
Teaching of Psychology \\
American Historical Review \\
English Literature in Transition, \\
1880-1920 \\
French Review \\
Journal of American Ethnic History \\
Journal of American History \\
Journal of College Student \\
Development \\
Journal of Symbolic Logic \\
Journalism Quarterly \\
Libraries and Culture \\
•Psychology in the Schools \\
Superconductor Science and \\
Technology \\
\hline -Title is on two lists. \\
\hline
\end{tabular}

Not surprisingly, the library subscribes to all the titles on this list.

The twenty-seven journals in which WIU faculty most frequently published (see table 3) contained 207 articles by WIU authors. Forty-four percent of all the ISIindexed articles published by authors affiliated with WIU appeared in these journals. Thirty articles were printed in the leading title (Journal of Developing Areas) as compared to four articles in each of the last eleven journals on the list (from
American Historical Review to Superconductor Science and Technology). There are no intersections between this list and either the student lists or the international list. A full 85 percent (twenty-three titles) appear on this list alone, making it the most distinctive list of all and therefore the least credible to use for selection decisions.

\section{Freshmen researchers evidently rely more on regional works than do the other groups ....}

Only the list of journals cited by WIU faculty contains any of the same titles; the two lists have four titles in commonJournal of Social Psychology, Psychological Reports, Journal of Parasitology, and Psychology in the Schools. All but two of the top journals in which faculty published are in the library's collection.

The twenty-four journals most frequently referenced by WIU authors in their published research (see table 4) were cited a total of 286 times, ranging from twenty-seven references to the first title (Journal of Personality and Social Psychology) to eight for each of the last titles (from Physic C to Social Problems). Fifteen journals $(63 \%)$ appear on this list alone. None of these titles was cited by freshmen, and only two (Nature and Science) were retrieved by students from InfoTrac. As mentioned earlier, four titles also appear on the list of journals publishing articles by WIU faculty. Interestingly, only five titles $(21 \%)$ were also on the $J C R$ list of most cited journals. The divergence between sources most frequently cited by WIU professors and those by researchers around the world dramatizes the importance of a local study. The WIU Library subscribes to twenty-three of the twenty-four most frequently cited journals.

During the five years of this study, the most cited journal reported by JCR, Journal of Biological Chemistry, was cited 984,935 times, yet it did not appear on any 


\begin{tabular}{|c|}
\multicolumn{1}{c|}{ TABLE 4 } \\
Top Journals Cited in \\
Faculty Articles, in Ranked Order \\
\hline \hline Journal of Personality \& Social \\
Psychology \\
Psychological Bulletin \\
\#Science \\
American Sociological Review \\
Journal of Applied Psychology \\
•Psychological Reports \\
\#Nature \\
American Journal of Sociology \\
Journal of Social Issues \\
-Journal of Social Psychology \\
American Midland Naturalist \\
Organizational Behavior and Human \\
Decision Processes \\
American Economic Review \\
American Psychologist \\
•Journal of Parasitology \\
•Physical Review B \\
•Physical Review Letters \\
Geological Society of America Bulletin \\
Journal of Abnormal Psychology \\
Physic C \\
•Proceedings of the National Academy of \\
the Sciences USA \\
•Psychology in the Schools \\
Social Forces \\
Social Problems \\
•Title is on two lists. \\
\#Title is on three lists. \\
\hline
\end{tabular}

of the local lists (see table 5). Only one title from this list (New England Journal of Medicine) is on the list of journals students cited, and three appear on the list of journals retrieved from InfoTrac (Nature, Science, and Lancet). The closest relationship exists with the titles cited by WIU faculty (five, or 19\%), but the comparatively small percentage of common titles is worth noting. The fact that this list contains the second largest number of unique titles (eighteen, or $72 \%$ ) is not surprising, given that international citations are so heavily weighted to journals in the hard sciences and medicine. WIU citations may not correspond to international citations largely

\begin{tabular}{|l|}
\multicolumn{1}{c|}{ TABLE 5 } \\
Journals Most Frequently Cited in \\
Published Articles Worldwide, in \\
Ranked Order \\
\hline \hline Journal of Biological Chemistry \\
•Proceedings of the National Academy of \\
the Sciences USA \\
\#Nature \\
\#Science \\
Journal of the American Chemical \\
Society \\
Journal of Chemical Physics \\
•Physical Review Letters \\
Cell \\
•Physical Review B \\
•New England Journal of Medicine \\
•Lancet \\
Journal of Immunology \\
Biochimica et Biophysica Acta \\
Biochemistry-US \\
American Journal of Physiology \\
Brain Research \\
Journal of Clinical Investigation \\
Cancer Research \\
Astrophysical Journal \\
Journal of Cell Biology \\
Biochemical and Biophysical Research \\
Communications \\
Biochemical Journal \\
Journal of Physical Chemistry-US \\
Nucleic Acids Research \\
Journal of Experimental Medicine \\
-Title is on two lists. \\
\#Title is on three lists. \\
\hline
\end{tabular}

because the university has comparatively small departments in chemistry and physics and no medical program. WIU Library subscribes to nineteen $(76 \%)$ of these heavily cited journals.

\section{Conclusions}

The dissimilarity between the comprehensive JCR citation list and any of the WIU lists emphasizes the folly of making local collection development decisions based on national or international data. Particularly at colleges and smaller universities, where collections are necessar- 
ily less comprehensive, the distinctive combination of programs and disciplines heavily influences the resources required by the campus community. Local use differs substantially from use in general and, therefore, must continue to be studied if individual institutions are to make informed decisions about their own specialized needs. Fortunately, electronic resources can facilitate the gathering and evaluating of local data, making such studies simpler and more accurate than in the past.

The authors' findings add an additional dimension to the local versus universal debate. Even a local study may offer a distorted reflection of use if it only mirrors the habits of one user type. The lists illustrate that use differs even among local constituencies. WIU faculty and students do not consistently consult the same journals in their research. Although a few favorites overlap several of the lists, the majority of titles are unique to one list. This evidence of the varied journal consultation habits of different groups confirms that a single measurement of journal usage is not effective. Aspiring to compile a concise list of "core" journals is to place trust in a mirage; there does not appear to be a compact "core list" of journal titles that will satisfy the needs of an entire university community.

The close relationship between InfoTrac retrieval and freshman citations reinforces the theory that students find much of their journal literature through periodical indexes. Thus, using popular indexes as tools for journal selection will build collections that will satisfy the needs of most undergraduate researchers. The authors' study also demonstrates that students are more likely to choose resources based on convenience, as documented by their reliance on local newspapers and journals held by the WIU Library. In light of this finding, collection managers should proceed with caution when contemplating the acquisition of general-interest, full-text databases. As Adele F.
Bane observed, "content clearly becomes secondary to convenience" when students have electronic access to complete articles. "Students will modify their topics or ignore relevant bodies of information" when given the option of retrieving articles from a CD-ROM rather than a printed source. ${ }^{6}$ Obviously, libraries must continue to provide basic, readily available material to satisfy the needs of beginning students, but making some sources more convenient than others can have serious consequences for teaching research skills to fledgling scholars.

Because the student and faculty lists do not closely correspond, subscribing only to what students use would do a severe disservice to faculty. The specialized needs of the faculty must be considered if the library is to support the professional development of the university's researchers. The model of the university as the place where knowledge is created, not just passed on, depends on the intellectual activity of the faculty. Their interests are more detailed, more precise, and more scattered than those of students. Librarians must endeavor to provide faculty with the material they need for their scholarly research, by either subscribing to the most important journals in their fields or offering another method of timely and convenient access to them.

The five lists assembled here demonstrate that even within one academic library, journal usage varies immensely and the needs of library patrons are diverse. Collection development, therefore, will never be reduced to a quantitative equation. In the words of Paul Metz, "neither formulas nor use statistics alone, nor intuition, experience, or pseudo-scholarship alone will suffice in building good collections." Still, the study of who uses what is essential. The electronic methods employed here, though not foolproof, have provided solid, reasonably gathered data to contribute to journal selection and deselection decisions. As interdisciplinary intermediaries and resource specialists, li- 
brarians must continue to explore the needs of different contingents within the university in order to develop and maintain balanced, useful journal collections.

\section{Notes}

1. "Expanded Academic Index/ASAP," in Information Access Company Homepage (World Wide Web site); available from URL http://www.iacnet.com/ lib/product/exacinas.html (cited Feb. 21, 1996).

2. Margaret Sylvia and Marcella Lesher, "What Journals Do Psychology Graduate Students Need? A Citation Analysis of Thesis References, "College \& Research Libraries 56 (July 1995): 31318.

3. Robert N. Broadus, "A Proposed Method for Eliminating Titles from Periodical Subscription Lists," College \& Research Libraries 46 (Jan. 1985): 30-35.

4. Stephanie C. Haas and Kate Lee, "Research Journal Usage by the Forestry Faculty at the University of Florida, Gainesville," Collection Building 11, no. 2 (1991): 23-25.

5. Keith Swigger and Adeline Wilkes, "The Use of Citation Data to Evaluate Serials Subscriptions in an Academic Library," Serials Review 17 (summer 1991): 41-52.

6. Adele F. Bane, "Business Periodicals Ondisc: How Full-Text Availability Affects the Library," Computers in Libraries 15 (May 1995): 54-56.

7. Paul Metz, "Thirteen Steps to Avoiding Bad Luck in a Serials Cancellation Project," Journal of Academic Librarianship 18 (May 1992): 76-82. 